\title{
Correction to: Genomics of NSCLC patients both affirm PD-L1 expression and predict their clinical responses to anti-PD-1 immunotherapy
}

Kim A. Brogden ${ }^{1 *}$, Deepak Parashar ${ }^{2}$, Andrea R. Hallier ${ }^{3}$, Terry Braun ${ }^{3}$, Fang Qian ${ }^{1,4}$, Naiyer A. Rizvi ${ }^{5}$, Aaron D. Bossler ${ }^{6}$, Mohammed M. Milhem ${ }^{7}$, Timothy A. Chan ${ }^{8}$, Taher Abbasi ${ }^{9}$ and Shireen Vali ${ }^{9}$

\section{Correction}

It has been highlighted that in the original manuscript [1] Table S3 'An example of the predictive computational modeling process. Specific details on an annexure section of the PD-L1 pathway show the step-by-step reactions, mechanisms, and reaction equations that occur. Such reactions also occurred in all of the other pathways' was omitted and did not appear in the Additional files. The original article has been updated.

\begin{abstract}
Author details
'lowa Institute for Oral Health Research, College of Dentistry, The University of lowa, 801 Newton Road, lowa City, IA 52242, USA. ${ }^{2}$ Cellworks Research India Ltd., Whitefield, Bangalore 560066, India. ${ }^{3}$ Biomedical Engineering, The University of lowa, 5318 SC, lowa City, IA 52242, USA. ${ }^{4}$ Division of Biostatistics and Research Design, College of Dentistry, The University of lowa, 801 Newton Road, lowa City, IA 52242, USA. ${ }^{5}$ Division of Hematology/Oncology, Columbia University Medical Center, 177 Fort Washington Avenue, New York, NY 10032, USA. ${ }^{6}$ Molecular Pathology Laboratory, Department of Pathology, University of lowa Hospitals and Clinics, 200 Hawkins Dr., C606GH, lowa City, IA 52242, USA. ${ }^{7}$ Clinical Services, Experimental Therapeutics, Melanoma and Sarcoma Program, Holden Comprehensive Cancer Center, The University of lowa, lowa City, IA 52242, USA. ${ }^{8}$ Department of Radiation Oncology, Human Oncology and Pathogenesis Program, Immunogenomics and Precision Oncology Platform, Memorial Sloan Kettering Cancer Center, New York, NY 10065, USA. ${ }^{9}$ Cellworks Group, Inc., 2033 Gateway Place Suite 500, San Jose, CA 95110, USA.
\end{abstract}

Published online: 12 April 2018

\section{Reference}

1. Brogden KA, et al. Genomics of NSCLC patients both affirm PD-L1 expression and predict their clinical responses to anti-PD-1 immunotherapy. BMC Cancer. 2018;18:225. https://doi.org/10.1186/s12885-018-4134-y.

\footnotetext{
* Correspondence: kim-brogden@uiowa.edu

'lowa Institute for Oral Health Research, College of Dentistry, The University of lowa, 801 Newton Road, lowa City, IA 52242, USA
} 